\title{
Anemi nedeniyle yapılan gastroskopi ve kolonoskopi sonuçlarının değerlendirilmesi
}

\section{Evaluation of the results of gastroscopic and colonoscopic examinations done because of anemia}

\author{
Mehmet BAYRAM, Ali Rıza KÖKSAL, Salih BOĞA, Hüseyin ALKIM, Ilker ŞEN, Canan ALKIM
}

Şişli Hamidiye Etfal Eğitim ve Araștırma Hastanesi, Gastroenteroloji Kliniği, Istanbul

Giriş ve Amaç: Anemi etiyolojisini araștirmada özofagogastroduodenoskopi (gastroskopi) ve kolonoskopi yapılması gerekli olan tetkiklerdir. Endoskop ünitemizde anemi nedeniyle yapılan gastroskopi ve kolonoskopi işlemlerinin sonuçlarını retrospektif olarak değerlendirmeyi amaçladık. Gereç ve Yöntem: Ocak 2012-Aralık 2013 tarihleri arasında Sişli Hamidiye Etfal Eğitim ve Araştırma Hastanesi Gastroenteroloji Kliniği endoskopi ünitesinde anemi endikasyonu ile yapılmıs olan 545 gastroskopi ve 398 kolonoskopi işleminin sonuçları retrospektif olarak bilgisayar veri tabanından elde edildi. Bulgular: Anemi nedeniyle gastroskopi istenen 545 hastanin 214'ü (\%39) erkek ve

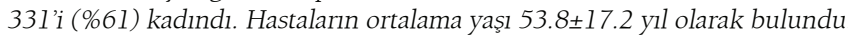
$\mathrm{Bu}$ hastaların toplam \%27.2'sinde özofagus varisi, mide kanseri, gastroduodenal ülser, angiodisplazi ve geçirilmiş mide ameliyatı gibi anemiyi açıklayabilecek patoloji saptandı. Bu oran kadın hastalarda \%20, erkek hastalarda \%39 olarak; 50 yaş altı hastalarda \%19, 50 yaş üstü hastalarda \%34 olarak bulundu. Anemi nedeniyle kolonoskopi yapılan 398 hastanın 171'i (\%43) erkek ve 227'si (\%57) kadınd. Hastaların ortalama yass $56.9 \pm 15.7$ yıl idi. Kolonoskopi yapilan hastaların \%40.5'inde anemiye sebep olabilecek patoloji saptandr. Bu oran kadın hastalarda \%33.5, erkek hastalarda \%49.7 olarak; 50 yaş altı hastalarda \%22, 50 yaş üstü hastalarda \%49.1 olarak bulundu. Anemi nedeniyle gastroskopi yapılan hastalarm \%1.8'inde malignite saptanırken, kolonoskopi yapılan hastaların ise \%3.3'ünde malignite, \%21.6'sında polip saptandı. Sonuç: Demir eksikliği anemisi etiyolojisi araștırmak için yapilan alt ve üst gastrointestinal sistem endoskopik incelemeleri ile 50 yaş üstü ve erkek hasta grubunda anemiyi açıklayacak patoloji saptama oranı daha yüksektir.

Anahtar kelimeler: Anemi, gastroskopi, kolonoskopi

\section{GİRIS}

Anemi Dünya Sağlık Örgütü (WHO) tarafından erişkinler için hemoglobin düzeyinin erkeklerde $13 \mathrm{~g} / \mathrm{dl}$, kadınlarda 12 g/dl'den düşük olması olarak tanımlanmıştır (1). Demir eksikliği anemisi en sık görülen anemi türü olup gelişmiş ülkelerdeki sıklığ1 \%8'dir (2). Erişkin erkek ve postmenopozal kadınlarda demir eksikliği anemisinin en sık sebebi gastrointestinal kayılardır $(3,4)$. Bu hasta grubunda demir eksikliği anemisi sıklığı \%2-5 arasında değişmektedir (5). Demir eksikliği anemisi olan hastalarda yapılan gastrointestinal sistem endoskopik incelemelerinde malignite saptanma oranı

Bayram M, Köksal AR, Boğa S, et al. Evaluation of the results of gastroscopic and colonoscopic examinations done because of anemia. Endoscopy Gastrointestinal 2015;23:31-34.
Background and Aims: Oesophagogastroduodenoscopy (gastroscopy) and colonoscopy are examinations required for the evaluation of the etiology of anemia. We aimed to retrospectively evaluate results of gastroscopic and colonoscopic examinations done in our endoscopy unit for the investigation of anemia. Materials and Methods: Retrospective data from 545 gastroscopy and 398 colonoscopy examinations done in the Endoscopy Unit of Sişli Hamidiye Etfal Training and Research Hospital Gastroenterology Department between January 2012 and December 2013 with an indication of anemia were obtained from our computer database. Results: Gastroscopy was performed on 545 patients because of anemia, of whom 214 (39\%) were male and 331 (61\%) were female. The average age of the patients was $53.8 \pm 17.2$ years. In $27.2 \%$ of these patients, diseases such as oesophageal varices, gastric cancer, gastroduodenal ulcer, angiodisplasia and previous gastric surgery that could explain anemia were detected. This ratio was 20\% in female patients, $39 \%$ in male patients, $19 \%$ in patients younger than 50 years and 34\% in patients 50 years and over. Colonoscopy was done in 398 patients because of anemia, of whom 171 (43\%) were male and 227 (57\%) were female. The average patient age was $56.9 \pm 15.7$ years. In $40.5 \%$ of patients undergoing colonoscopy, a pathology that may cause anemia was detected. This ratio was $33.5 \%$ in female patients, $49.7 \%$ in male patients, $22 \%$ in patients younger than 50 years and $49.1 \%$ in patients 50 years or over. While malignancy was detected in $1.8 \%$ of patients undergoing gastroscopy due to anemia, $3.3 \%$ malignancy and $21.6 \%$ polyp were detected in patients undergoing colonoscopy. Conclusion: In the upper and lower gastrointestinal system, endoscopic examinations done for the investigation of iron deficiency anemia etioogy and the detection rate of a pathology that could explain anemia was higher in patients 50 years or older and in male patients.

Key words: Anemia, gastroscopy, colonoscopy

\%6 ile \%11.2 arasında değişen oranlarda bildirilmiştir (6). Biz de endoskopi ünitemizde anemi etiyoloji nedeniyle yapmiş olduğumuz özofagogastroduodenoskopi (gastroskopi) ve kolonoskopi işlemlerini retrospektif olarak tarayıp anemiyi açıklayacak lezyon ve malignite saptama sıklı̆̆ımızı araştırmayı amaçladık.

\section{GEREC ve YÖNTEM}

Ocak 2012-Aralık 2013 tarihleri arasında Şişli Hamidiye Etfal Eğitim ve Araştırma Hastanesi Gastroenteroloji Kliniği 
endoskopi ünitesinde anemi etiyoloji endikasyonu ile yapılmış olan gastroskopi ve kolonoskopi işlemlerinin sonuçları retrospektif olarak bilgisayar veri tabanından taranarak elde edildi. Isslem tarihindeki hemoglobin düzeyinin erkeklerde 13 g/dl, kadınlarda 12 g/dl'den düşük olan, plazma demir ve ferritin düzeyi düşük olan hastalar değerlendirilmeye alındı. Aktif gastrointestinal sitem kanaması veya bilinen kanama yapabilecek (malignite, inflamatuvar barsak hastalığ veya angiodisplazi gibi) hastalığı olan hastalar çalışma dışı tutuldu.

\section{BULGULAR}

Ocak 2012 - Aralık 2013 tarihleri arasında Şişli Hamidiye Etfal Eğitim ve Araştırma Hastanesi Gastroenteroloji Kliniği endoskopi ünitesinde anemi endikasyonu ile yapılmış olan 545 gastroskopi ve 398 kolonoskopi işleminin sonuçları değerlendirmeye alındı.

Anemi nedeniyle gastroskopi yapılan 545 hastanın 214'ü (\%39) erkek ve 331'i (\%61) kadındı. Hastaların ortalama yaşı $53.8 \pm 17.2$ (16-96) yl olarak bulundu. Gastroskopik incelemede saptanan patolojiler Tablo l'de özetlenmiştir. Değerlendirilen 545 gastroskopi işleminin 7'sinde (\%1.3) özofagus varisi, 44'ünde (\%8.1) ciddi eroziv gastrit, 18'inde (\%3.4) gastrik ülser, 10'unda (\%1.8) mide kanseri, 25'inde (\%4.6) duodenal ülser, 25 'inde (\%4.6) duodenit, 3'ünde (\%0.6) angiodisplazi, 16'sinda (\%2.9) opere mide (Billroth II), 397'sinde (\% 72.8) anemiyle ilişkisiz hiatus hernisi ve antral gastrit gibi diğer patolojiler saptandı.

Cinsiyete göre (Tablo 2) gastroskopik bulgulara bakıldığında erkeklerde yapilan 214 gastroskopik incelemenin 4'ünde (\%1.9) özofagus varisi, 22'sinde (\%10.3) ciddi eroziv gastrit, 7 'sinde $(\% 3,3)$ gastrik ülser, 8'inde $(\% 3.7)$ mide kanseri, 14'ünde (\%6.5) duodenal ülser, 11'inde (\%5.1) duodenit, 2'sinde $(\% 0,9)$ angiodisplazi, 14'ünde $(\% 6.5)$ opere mide (Billroth II) saptanırken 132'sinde (\%61) anemiyi açılkayacak anlamlı endoskopik patoloji bulunamadı. Kadın hastalar-

\section{Tablo 1. Üst gastrointestinal sistem endoskopik}

incelemede saptanan lezyonlar

\begin{tabular}{|lc}
\hline Gastroskopik Tanı & n (545) \\
\hline Özofagus varisi & $7(\% 1.3)$ \\
\hline Ciddi eroziv gastrit & $44(\% 8.1)$ \\
\hline Mide ülseri & $18(\% 3.3)$ \\
Mide kanseri & $10(\% 1.8)$ \\
Opere mide & $16(\% 2.9)$ \\
Duodenum ülseri & $25(\% 4.6)$ \\
Duodenit & $25(\% 4.6)$ \\
\hline Angiodisplazi & $3(\% 0.6)$ \\
Diğer & $397(\% 72.8)$
\end{tabular}

Tablo 2. Üst gastrointestinal sistem endoskopik incelemede saptanan lezyonların cinsiyete göre dağılımı

\begin{tabular}{lcc}
\hline Gastroskopik Tanı & Erkek (n:214) & Kadın (n:331) \\
Özofagus varisi & $4(\% 1.9)$ & $3(\% 0.9)$ \\
Ciddi eroziv gastrit & $22(\% 10.3)$ & $22(\% 6.6)$ \\
Mide ülseri & $7(\% 3.3)$ & $11(\% 3.3)$ \\
Mide kanseri & $8(\% 3.7)$ & $2(\% 0.6)$ \\
Opere mide & $14(\% 6.5)$ & $2(\% 0.6)$ \\
Duodenum ülser & $14(\% 6.5)$ & $11(\% 3.3)$ \\
Duodenit & $11(\% 5.1)$ & $14(\% 4.2)$ \\
Angiodisplazi & $2(\% 0.9)$ & $1(\% 0.3)$ \\
Diğer & $132(\% 61)$ & $265(\% 80)$
\end{tabular}

da yapılan 331 gastroskopi işleminin 3'ünde (\%0.9) özofagus varisi, 22'sinde (\%6.6) ciddi eroziv gastrit, 11 'inde (\%3.3) gastrik ülser, 2'sinde (\%0.6) mide kanseri, 11 'inde (\%3.3) duodenal ülser, 14'ünde (\%4.2) duodenit, l'inde (\%0.3) angiodisplazi, 2'sinde (\%0.6) opere mide (Billroth II) mevcuttu. Kadın hastaların 265'inde (\%80) anlamlı gastroskopik patoloji saptanamadi.

Hastalar 50 yaş altı ve 50 yaş ve üzeri diye ikiye ayrılıp incelendiğinde gastroskopik olarak saptanan patolojiler Tablo 3'de verilmektedir. Elli yaş altı 225 hastada anemi nedeniyle yapılan gastroskopik incelemelerin l'inde (\%0.4) özofagus varisi, 13'ünde (\%5.8) ciddi eroziv gastrit, 5 'inde (\%2.2) gastrik ülser, 2'sinde (\%0.9) mide kanseri, 6'sinda (\%2.7) duodenal ülser, 13'ünde (\%5.8) duodenit, l'inde (\%0.4) opere mide (Billroth II) saptanırken, 184'ünde (\%81) anlamlı patoloji saptanmadı. Elli yaş ve üzeri 320 hastada yapılan gastroskopik işlemlerin 6'sında (\%1.9) özofagus varisi, 31'inde (\%9.7) ciddi eroziv gastrit, 13'ünde (\%4.1) gastrik ülser, 8'inde (\%2.5) mide kanseri, 19'unda (\%5.9) duodenal ülser,

Tablo 3. Üst gastrointestinal sistem endoskopik incelemede saptanan lezyonların yaşa göre dağılımı

$\begin{array}{lcc}\text { Gastroskopik Tanı } & <50 \text { yaş (n:225) } & \geq 50 \text { yaş (n:320) } \\ \text { Özofagus Varisi } & 1(\% 0.4) & 6(\% 1.9) \\ \text { Ciddi Eroziv Gastrit } & 13(\% 5.8) & 31(\% 9.7) \\ \text { Mide Ülseri } & 5(\% 2.2) & 13(\% 4.1) \\ \text { Mide Kanseri } & 2(\% 0.9) & 8(\% 2.5) \\ \text { Opere Mide } & 1(\% 0.4) & 15(\% 4.7) \\ \text { Duodenum Ülser } & 6(\% 2.7) & 19(\% 5.9) \\ \text { Duodenit } & 13(\% 5.8) & 12(\% 3.8) \\ \text { Angiodisplazi } & 0(\% 0) & 3(\% 0.9) \\ \text { Diğer } & 184(\% 81) & 213(\% 66)\end{array}$


12 'sinde (\%3.8) duodenit, 3'ünde $(\% 0,9)$ angiodisplazi, 15 inde (\%4.7) opere mide (Billroth II) bulunurken geri kalan 213 (\%66) hastada anemi yönünden anlamlı patoloji yoktu.

Anemi tetkik nedeniyle kolonoskopi istenen 398 hastanın 171 'i (\%43) erkek ve 227'si (\%57) kadındı. Hastaların orta-

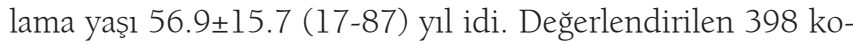
lonoskopi işleminin 237'sinde (\%59.5) normal kolonoskopik bulgular, 86'sında (\%21.6) kolon polipleri, 13'ünde (\%3.3) kolon kanseri, 8'inde (\%2) inflamatuvar barsak hastalığl, l'inde $(\% 0,3)$ angiodisplazi, l'inde $(\% 0,3)$ soliter rektal ülser ve 52 'sinde (\% 13.1) hemoroid saptandi. Kolonoskopide saptanan patolojiler Tablo 4'de özetlenmiştir.

Cinsiyete göre bakıldığında erkek hastalara yapılan 171 kolonoskopi işleminin 86'sında (\%50.3) normal kolonoskopik bulgular, 5l'inde (\%29.8) kolon polipleri, 7'sinde (\%4.1)

\begin{tabular}{lc} 
Tablo 4. Kolonoskopide saptanan lezyonların dağılımı \\
\hline Kolonoskopik tanı: & n (398) \\
Normal kolonoskopi & $237(\% 59.5)$ \\
Kolon polipleri & $86(\% 21.6)$ \\
Kolon kanseri & $13(\% 3.3)$ \\
Inflamatuvar barsak hastalığı & $8(\% 2)$ \\
Angiodisplazi & $1(\% 0.3)$ \\
Soliter rektal ülser & $1(\% 0.3)$ \\
Hemoroid & $52(\% 13.1)$
\end{tabular}

kolon kanseri, 3'ünde (\%1.8) inflamatuvar barsak hastalığl, l'inde (\%0.6) angiodisplazi, 23'ünde (\%13.5) hemoroid saptand. Kadın hastalara yapılan 227 kolonoskopi işleminin 15l'inde (\%59.5) normal kolonoskopik bulgular, 35'inde (\%15.4) kolon polipleri, 6'sinda (\%2.6) kolon kanseri, 5'inde (\%2.2) inflamatuvar barsak hastalığ1, l'inde (\%0.3) soliter rektal ülser ve 29 hastada (\% 12.8) hemoroid saptandı. Kolonoskopide saptanan lezyonların cinsiyete göre dağılımı Tablo 5'de gösterimektedir. Yaşa göre bakıldı̆̆ında (Tablo 6) 50 yaş

\begin{tabular}{|c|c|c|}
\hline Kolonoskopik tanı: & Erkek (n:171) & Kadın (n:227) \\
\hline Normal kolonoskopi & $86(\% 50.3)$ & $151(\% 66.5)$ \\
\hline Kolon polipleri & $51(\% 29.8)$ & $35(\% 15.4)$ \\
\hline Kolon kanseri & $7(\% 4.1)$ & $6(\% 2.6)$ \\
\hline $\begin{array}{l}\text { Inflamatuvar barsak } \\
\text { hastalığ }\end{array}$ & $3(\% 1.8)$ & $5(\% 2.2)$ \\
\hline Angiodisplazi & $1(\% 0.6)$ & $0(\% 0)$ \\
\hline Soliter rektal ülser & $0(\% 0)$ & $1(\% 0.4)$ \\
\hline Hemoroid & $23(\% 13.5)$ & $29(\% 12.8)$ \\
\hline
\end{tabular}

Tablo 6. Kolonoskopide saptanan lezyonların yaşa göre dağılımı

\begin{tabular}{lcc|} 
Kolonoskopik Tanı & $<50$ yaş (n:127) & $\geq 50$ yaş (n:271) \\
\hline Normal kolonoskopi & $99(\% 78)$ & $138(\% 50.9)$ \\
Kolon polipleri & $9(\% 7.1)$ & $77(\% 28.4)$ \\
Kolon kanseri & $0(\% 0)$ & $13(\% 4.8)$ \\
$\begin{array}{l}\text { Inflamatuvar barsak } \\
\text { hastalığ }\end{array}$ & $3(\% 2.4)$ & $5(\% 1.8)$ \\
Angiodisplazi & $0(\% 0)$ & $1(\% 0.4)$ \\
Soliter rektal ülser & $0(\% 0)$ & $1(\% 0.4)$ \\
Hemoroid & $16(\% 12.6)$ & $36(\% 13.3)$
\end{tabular}

altı 127 kolonoskopi işleminin 99'unda (\%78) normal kolonoskopik bulgular, 9'unda (\%7.1) kolon polipleri saptandi. $\mathrm{Bu} 50$ yaş altı hasta grubunda kolon kanseri, angiodisplazi ve soliter rektal ülser saptanmazken 3 hastada (\%2.4) inflamatuvar barsak hastalığı ve 16 hastada (\%12.6) hemoroid saptandı. Elli yaş ve üzeri 271 hastaya yapılan kolonoskopi işlemlerinin 138'inde (\%50.9) normal kolonoskopik bulgular, 77 'sinde (\%28.4) kolon polipleri, 13'ünde (\%4.8) kolon kanseri, 5 'inde (\%2) inflamatuvar barsak hastalığı, l'inde (\%0.4) angiodisplazi, l'inde (\%0.4) soliter rektal ülser ve 36'sinda (\%13.3) hemoroid saptandi.

Kolon polipleri ve kanser birlikte ele alındığında hastaların \%25'inde (99 hastada) neoplastik lezyon saptandığı görüldü. Kadın hastaların \%18'inde neoplastik lezyon saptanırken erkek hastaların \%34'ünde neoplastik lezyon bulundu. Elli yaş altı hastalarda sadece \% 7.1 oranında neoplastik lezyon (hepsi polip) saptanırken, elli yaş ve üzerinde bu oran yine \%34'e çıkıyordu.

\section{TARTIŞMA}

Demir eksikliği anemisi en sık görülen anemi türüdür ve dünyada 2 milyara yakın kişide görüldüğü tahmin edilmektedir (7). Premenopozal kadınlarda en sik sebep menstruasyon ile kayıp iken, erkeklerde ve postmenopozal kadınlarda gastrointestinal sistemden kayıp en önemli sebeptir (2,3). Demir eksikliği anemisi olan hastalarda etiyolojik neden endoskopik yöntemlerle \%76.1 hastada saptanabilmektedir (8). Ülkemizde yapılmış bir çalışmada anemisi olan erkek ve postmenopozal kadınların üçte ikisinde endoskopik yöntemlerle sebep olabilecek lezyon saptandığı bildirilmiştir (9). Kadın hasta ağırlıklı ve ortalama yaş 43 olan başka bir çalışmada hemoroid hariç anemi yapabilecek endoskopik lezyon saptanma oranı \% 18.6 bulunmuştur (10).

Bizim çalışmamızda gastroskopi yapılan hastaların \%27.2'sinde özofagus varisi, ciddi eroziv gastrit, gastroduodenal ülser, mide kanseri, angiodisplazi ve geçirilmiş mide ameliyatı gibi anemiyi açıklayabilecek patoloji saptandı. Bu oran ka- 
dın hastalarda \%20, erkek hastalarda \%39 olarak; 50 yaş altı hastalarda \%19, 50 yaş üstü hastalarda \%34 olarak bulundu. Anemi nedeniyle kolonoskopi yapılan hasta grubumuzda hemoroid saptanan hastalar da dahil edildiğinde \%40.5 hastada anemiye sebep olabilecek patoloji saptandi. Bu oran kadın hastalarda \%33.5, erkek hastalarda \%49.7 olarak; 50 yaş altı hastalarda \%22, 50 yas üstü hastalarda \%49.1 olarak bulundu. Rakamlar literatüre göre düşük görünmekle birlikte çalışmamızda gastroskopi ve kolonoskopi sonuçları ayrı ayrı değerlendirildi. Aynı hastaya hem gastroskopi hem kolonoskopi yapıldığında anemi yapabilecek patoloji saptama olasılığı artacaktır. Ayrıca 50 yaş üzeri hasta grubu ile erkek hasta grubunda saptanan patolojilerin oranı literatüre benzerdir.

Gelişmiş ülkelerde demir eksikliği anemisi nedeni ile yapılan endoskopik işlemlerle malignite bulma oranı \%6 ile \%11.2 arasında değişmektedir $(6,11)$. Ülkemizde yapılan bir çalışmada demir eksikliği anemisi olan hastalarda gastroskopide malignite saptanma sıklı̆ı \%0.9 kolonoskopi yapılan hastalarda \%4.7 olarak bildirilmiştir. Yine bu çalışmada kolonoskopide polip saptanma sıklığı \%45'dir (12).

Bizim çalışmamızda malignite saptanma oranı gastroskopide \%1.8, kolonoskopide \%3.3 olarak bulundu. Kolonoskopide polip saptama sıklığımız ise \%21.6'dır. Bu oranlar ülkemizdeki çalışmaya benzer iken yabancı çalışmadakinden düşüktür. Erkek hastalarda mide kanseri \%3.7, kolon kanseri \%4.1 oranındayken, kadın hastalarda mide kanseri \%0.6, kolon kanseri \%2.6 oranında bulunmuştur. Sağlık Bakanlığının kanser istatistiklerine göre hem mide hem kolon kanseri erkek popülasyonda daha sıktır (13). Elli yaş altı hastalarda mide kanseri saptanma oranı \%0.9 iken, 50 yaş üzerinde \%2.5'e çıkmaktadır. Kolon kanseri saptanma oranı 50 yaş altında sıfır iken 50 yaş ve üzerinde \%4.8 olarak bulunmuştur. Bu sonuçlar da uluslararası kılavuzlarda da önerildiği üzere 50 yaş üzeri hasta popülasyonunda malignite açısından tarama yapmanın uygun yaklaşım olacağını göstermektedir $(14,15)$. Ayrıca anemi nedeniyle kolonoskopi yapılan her dört hastanın birinde neoplastik lezyon (polip veya kanser) saptamış olduğumuzu da tekrar vurgulamak gereklidir.

Demir eksikliği anemisi etiyolojisi araştırmak amacıyla yapilan gastroskopi ve kolonoskopi incelemelerinde 50 yaş ve üzeri hastalar ile erkek hasta grubunda anemiyi açılkayacak patoloji saptama oranı daha yüksektir. Malignite tarama için de 50 yaş üstü hasta grubu daha uygun görünmektedir.

\section{KAYNAKLAR}

1. Beutler E, Waalen J. The definition of anemia: what is the lower limit of normal of the blood hemoglobin concentration? Blood 2006;107:1747-50.

2. Provan D. Mechanism and management of iron deficiency anemia. Br J Haematol 1999;105(Suppl 1):19-26.

3. Kepczyk T, Kadakia SC. Prospective evaluation of gastrointestinal tract in patients with iron-deficiency anemia. Dig Dis Sci 1995;40:1283-9.

4. Hardwick RH, Armstrong CP. Synchronous upper and lower gastrointestinal endoscopy is an effective meth $\neg$ od of investigating iron-deficiency anemia. Br J Surg 1997;84:1725-8

5. Looker AC, Dalman PR, Carroll MD, et al. Prevalance of iron deficiency anemia in United States. JAMA 1997;277:973-6.

6. James MW, Chen C-M, Goddard WP, et al. Risk factors for gastrointestinal malignancy in patients with iron-deficiency anaemia. Eur J Gastroenterol Hepatol 2005; 17:1197-203.

7. DeMaeyer E, Adiels-Tegman M. The prevalence of anaemia in the world. World Health Stat Q. [Comparative Study]. 1985;38:302-16.

8. Milano A, Balatsinou C, Filippone A, et al. A prospective evaluation of iron deficiency anemia in the GI endoscopy setting: Role of Standard endoscopy, videocapsule endoscopy, and CT-enteroclysis. Gastrointest Endosc 2011;73:1002-8.

9. Kurtoğlu E, Kayaçetin E, Uğur A. Demir Eksikliği Anemisi Saptanan Erkeklerde ve Postmenapozal Kadınlardaki Alt ve Üst Gastrointestinal Sistem Bulguları. MN Klinik Bilimler \& Doktor 2004;10(3):251-4

10. Serefhanoglu S, Buyukasik Y, Emmungil H, et al. Identification of clinical and simple laboratory variables predicting responsible gastrointestinal lesions in patients with iron deficiency anemia. Int J Med Sci 2010;28:30-8.

11. Ioannou GN, Rockey DC, Bryson CL, Weiss NS. Iron deficiency and gastrointestinal malignancy: A population-based cohort study. Am J Med 2002; 113:276-80.

12. Ünal ÜH, Fidan C, Korkmaz M, Selçuk H. Demir eksikliği olan hastalarda gastrointestinal sistem endoskopi bulguları. Akademik Gastroenteroloji Dergisi 2012; 3:113-6.

13. Türkiye Halk Sağlı̆̆ Kurumu Kanser Daire Başkanlığı Kanser Istatistikleri; kanser.gov.tr

14. Appropriate use of gastrointestinal endoscopy. A consensus statement from the American Society for Gastrointestinal Endoscopy. Gastrointest Endosc 2000:52(6):831-7.

15. Goddard AF, James MW, McIntyre AS, Scott BB on behalf of the BSG. Guidelines for the management of iron deficiency anemia. 2005 Available at: http://www.bsg.org.uk/pdf word-does/iron_def.pdf 